\title{
Identification and sequence analysis of five allexiviruses species infecting garlic crops in Brazil
}

\author{
Milena L. Oliveira, Bruno R. De Marchi, Tatiana Mituti, Marcelo A. Pavan \& Renate Krause-Sakate \\ Departamento de Produção Vegetal, Faculdade de Ciências Agronômicas, Universidade Estadual de São Paulo, Rua José \\ Barbosa de Barros 1780, 18610-307, Botucatu, SP, Brazil
}

Author for correspondence: Renate Krause-Sakate, e-mail: renatekrause@fca.unesp.br

\begin{abstract}
Garlic plants are naturally infected by a mixture of viruses, including allexiviruses. Symptomatic garlic plants with mosaic and distorted leaves from garlic producing regions in Brazil were analyzed for the presence of Garlic virus A (GarV-A), Garlic virus B (GarV-B), Garlic virus C (GarV-C), Garlic virus D (GarV-D) and Garlic mite-borne filamentous virus (GarMbFV), five allexivirus species previously reported in the country. Fifty-nine virus isolates from five distinct allexivirus species were identified and the complete coat protein region of each genome was sequenced. Mixed infections were very frequent and corresponded to $43 \%$ of the positive samples. The nucleotide identity of the coat protein ranged between $75 \%$ and $98 \%$ for GarV-A isolates, $83 \%$ and $90 \%$ for GarV-B, $69 \%$ and $98 \%$ for GarV-C, $87 \%$ and $97 \%$ for GarV-D, and $72 \%$ and $91 \%$ for GarMbFV.
\end{abstract}

Key words: Allium sativum, mixed infection, variability, virus.

Virus diseases of garlic (Allium sativum L.) are widespread throughout the world, causing serious losses to crop yields and quality. In Brazil, garlic is the fifth most economically important vegetable and largely cultivated in different geographical areas. The states of Goiás, Minas Gerais, Paraná and São Paulo are responsible for approximately $64 \%$ of the production (Agrianual, 2012).

Vegetative propagation of garlic favors the dissemination and accumulation of viruses in bulbs. Several filamentous viruses associated with mosaic symptoms have been reported from garlic plants, often in complex mixtures. These include species belonging to the genera Potyvirus and Carlavirus (both aphid-borne viruses) and Allexivirus (mite-borne viruses). In Brazil, the allexivirus species reported infecting garlic are Garlic virus A (GarV-A), Garlic virus $B$ (GarV-B), Garlic virus $C$ (GarV-C), Garlic virus $D$ (GarV-D), Garlic-mite filamentous virus (GarMbFV) (Nascimento et al., 2008) and more recently Garlic virus $X$ (GarV-X) (Oliveira et al., 2014). These viruses have a single component of a single-stranded, positive sense, RNA with a 3'-poly A tail, but differ in genome organization. They are about $9 \mathrm{~kb}$ in length encoding a large alpha-like replicase and six large ORFs (Adams et al., 2012).

Allexiviruses are transmitted by the mite Aceria tulipae. The vectors are moved passively by the wind and in the bulbs storage rooms (Van Dijk et al., 1991). The biological data concerning these viruses are limited and the economic significance of allexivirus infection is not well known (Katis et al., 2012). Allexiviruses mainly cause latent infections or very mild chlorotic stripes and mild mosaic in leaves of Allium species (Van Dijk \& Van der Vlugt, 1994; Van Dijk et al., 1991). It is known that stripes or other mild leaf deformations can be directly caused by Aceria tulipae (Katis et al., 2012).

The characterization of these viruses and their species differentiation has been hampered by the fact that they often occur in multiple infections and their separation for further studies is difficult (Katis et al., 2012). Recently, studies in Argentina showed that probably not all of them affect yield similarly. GarV-A causes significant crop losses to two garlic cultivars (Blanco IFFIVE and Morado INTA) ranging from 14 to $32 \%$, while GarV-C, under the conditions studied and in the cultivars tested, caused mild or no damage on garlic yield (Cafrune et al., 2006).

The objective of this work was to analyze the presence of allexiviruses and the genetic variability of isolates infecting garlic in Brazil. Forty-eight garlic plants were collected in Paraná (PR), 120 samples in Minas Gerais (MG), 42 in São Paulo (SP) and 29 in Goiás (GO) states. These areas represent $64 \%$ of all Brazilian production. Preferentially, plants with yellow stripes and distorted leaves, symptoms typically induced by A. tulipae in garlic plants, were collected, but also with mosaic symptoms that can be induced by a potyvirus or a carlavirus. Garlic leaves were stored at $-80^{\circ} \mathrm{C}$ until used. Total RNA was extracted from the leaf samples using the method described by Bertheau et al. (1998) or with the Total RNA Purification kit (Norgen Biotek). RT-PCR was performed initially with a universal primer pair (Cpallexi-senso2, 5'-CTA CCA CAA YGG NTC VTC-3', and Cpallexi-anti1, 5'-CAC NGC 
GTT RAA GAA RTC-3'), that directs the amplification of a partial coat protein fragment of $237 \mathrm{bp}$. Positive samples were then analyzed with specific primers for GarV-A, GarV-C, GarV-D (Melo Filho et al., 2004) that amplify a fragment of about $800 \mathrm{bp}$ from the coat protein $(\mathrm{CP})$ region from these viruses, and another primer pair for GarMbFV (Fayad-André et al., 2011) that amplifies a 762 bp fragment from the $\mathrm{CP}$ of this virus. Another primer pair (CPBS2, 5'GCA GAA TAA RCC CCC YTC-3', and CPBA1, 5'-RAA GGG TTT ATT CTG TTG-3') was designed to amplify a fragment of $430 \mathrm{bp}$ corresponding to the partial coat protein gene of GarV-B and used for a preliminary detection. Then, a specific primer pair (GarV-BS1, 5'-CTY YTA CAC TCC AAA TGT CCC-3', and GarV-BA2, 5'-GTR AAG GGT TTA TTC TGT TGG-3') was used to amplify a 980 bp fragment corresponding to the complete coat protein gene of GarV-B.

Primers were used in a one step RT-PCR using the PCR Master Mix Kit (Fermentas) and AMV reverse transcriptase (Avian myeloblastosis virus; Promega). In a final volume of $25 \mu \mathrm{l}, 12.5 \mu \mathrm{L}$ of PCR Master Mix $2 \times, 100$ $\mu \mathrm{M}$ of each primer, 1 unit of AMV reverse transcriptase (Promega) and $2.5 \mu \mathrm{L}$ of RNA were added. For universal primers the PCR steps were 40 cycles at $94^{\circ} \mathrm{C}$ for $40 \mathrm{~s}, 50^{\circ} \mathrm{C}$ for $50 \mathrm{~s}$ and $72^{\circ} \mathrm{C}$ for $40 \mathrm{~s}$, and for specific primers they were 40 cycles at $94^{\circ} \mathrm{C}$ for $30 \mathrm{~s}, 53^{\circ} \mathrm{C}$ for $30 \mathrm{~s}$ and $68^{\circ} \mathrm{C}$ for $90 \mathrm{~s}$. PCR products were analyzed by electrophoresis on $0.8 \%$ agarose gel using GelRed (Uniscience).

The PCR products of representative isolates from each state were purified from agarose gels using the QIAquick Gel Extraction Kit (Qiagen) and sequenced. When necessary they were cloned as follows: the purified PCR product was ligated to the plasmid vector pGEM-T Easy (Promega) and transformed into E. coli XL1 competent cells. The selected plasmids were purified with the Wizard Plus SV Minipreps DNA Purification System (Promega) and inserts were verified by restriction enzyme digestion. The PCR products or clones were sequenced using an ABI 3730 DNA Analyser (Applied Biosystems) and the reactions were performed with the BigDye Terminator v3.1 Cycle Sequencing kit (Applied Biosystems). Analyses were done with the BLAST algorithm (blast.ncbi.nlm.nih.gov/ Blast) and Clustal W (www.genome.jp/tools/clustalw/). Phylogenetic trees were constructed with the MEGA 5.2 program using the neighbor joining method with 2,000 bootstrap replicates.

From a total of 239 symptomatic plants, $123(52 \%)$ were positive for the presence of allexiviruses based on PCR (Table 1). GarV-A was found as the predominant species, followed by GarV-D. All five species were found in the sampled regions. Some samples were positive by PCR using the universal primers, but negative for GarV-A, GarV-B, GarV-C, GarV-D and GarMFV. These samples were infected by GarV-X, considered an exotic allexivirus until then (Oliveira et al., 2013).

Fifty three samples had mixed infections with the different species of allexivirus, and three of them were infected with all viruses: GarV-A, GarV-B, GarV-C, GarV-D and GarMbFV (Table 1). A single garlic plant co-infected with members of eight virus species, among these GarV-A, GarV-B, GarV-C and GarV-D, was described in Australia using Ilumina GaIIx technology (Wylie et al., 2012). Very often allexiviruses persist in the infected plants as multiple infections with carlaviruses and potyviruses. This coexistence may have a synergistic effect and lead to even higher yield losses (Katis et al., 2012). Perotto et al. (2010) verified that garlic yield decreases faster in plants previously infected with an allexivirus, exposed to natural conditions and then reinfected with other naturally occurring viruses, than in plants that initially are virus-free.

Among 59 positive samples for GarV-A, the CP of 19 isolates from different states were sequenced. The GarV-A isolates could be subdivided in two branches (Figure 1). One branch includes only Brazilian isolates, collected in Santa Juliana (MG), Guarapuava (PR) and Cristalina (GO), most closely related to GarV-A isolates from Australia (GenBank accession number JN019812) with 89 to $90 \%$ nucleotide sequence identity. The other branch includes Brazilian isolates from Guarapuava and Botucatu (SP), most closely related to isolates from Korea (AF478197) and Japan (NC_003375 and AB010300), as well as closely related to a GarV-A isolate from Australia (JQ899446) with 95 to 98\% nucleotide sequence identity. Based on the comparison done with ClustalW, the CP gene of group I isolates Grpv01 (JX488604), STJ01 (JX488611), STJ03 (JX488613), STJ02 (JX488612), STJ08 (JX488618), STJ18 (KF955561), STJ07 (JX488617), Grpv02 (JX488605), STJ05 (JX488615), STJ06(JX488616), STJ17 (KF955560), STJ04 (JX488614), STJ19 (KF955562) and Cris01 (KF955563) shared 9899.9\% nucleotide sequence identity, while those from group II shared 95\%-99.5\% identity. Between viruses from groups I and II identities ranged from 85 to $87 \%$. The GarV-A isolate described in Australia (JN019812) by Wylie et al. (2012) was closer to GarV-A isolates from group I ( $89 \%$ identity).

Twenty-six samples were positive for GarV-B and seven isolates from different regions were selected for sequencing of the CP gene. GarV-B collected in São Manuel (SP) (SM05, JX488623) shares 90\% nucleotide identity with an isolate of GarV-B described in Australia (JN019813; Wylie et al., 2012) and is phylogenetically related to this isolate (Figure 2A). Other isolates from São Manuel (SM01, JX488619; SM02, JX488620; SM03, JX488621; SM04, JX488622; and SM06, JX488624) and an isolate from Guarapuava (PR) (GrpV03, JX488625) were more closely related to an isolate from Korea (AF543829). The CP nucleotide sequence identity between the GarV-B isolates ranged between $83 \%$ and $90 \%$.

Among 41 positive samples found for GarV-C, the $\mathrm{CP}$ gene of twelve was sequenced. Nucleotide identities ranged from $68 \%$ to $98 \%$ for the complete coat protein region between Brazilian sequences of GarV-C compared with all sequences available in the database. Brazilian 
TABLE 1- Number of garlic samples analyzed and infected with Garlic virus A (GarV-A), Garlic virus B (GarV-B), Garlic virus C (GarV-C), Garlic virus D (GarV-D) and Garlic mite-borne filamentous virus (GarMbFV) in single and mixed infections.

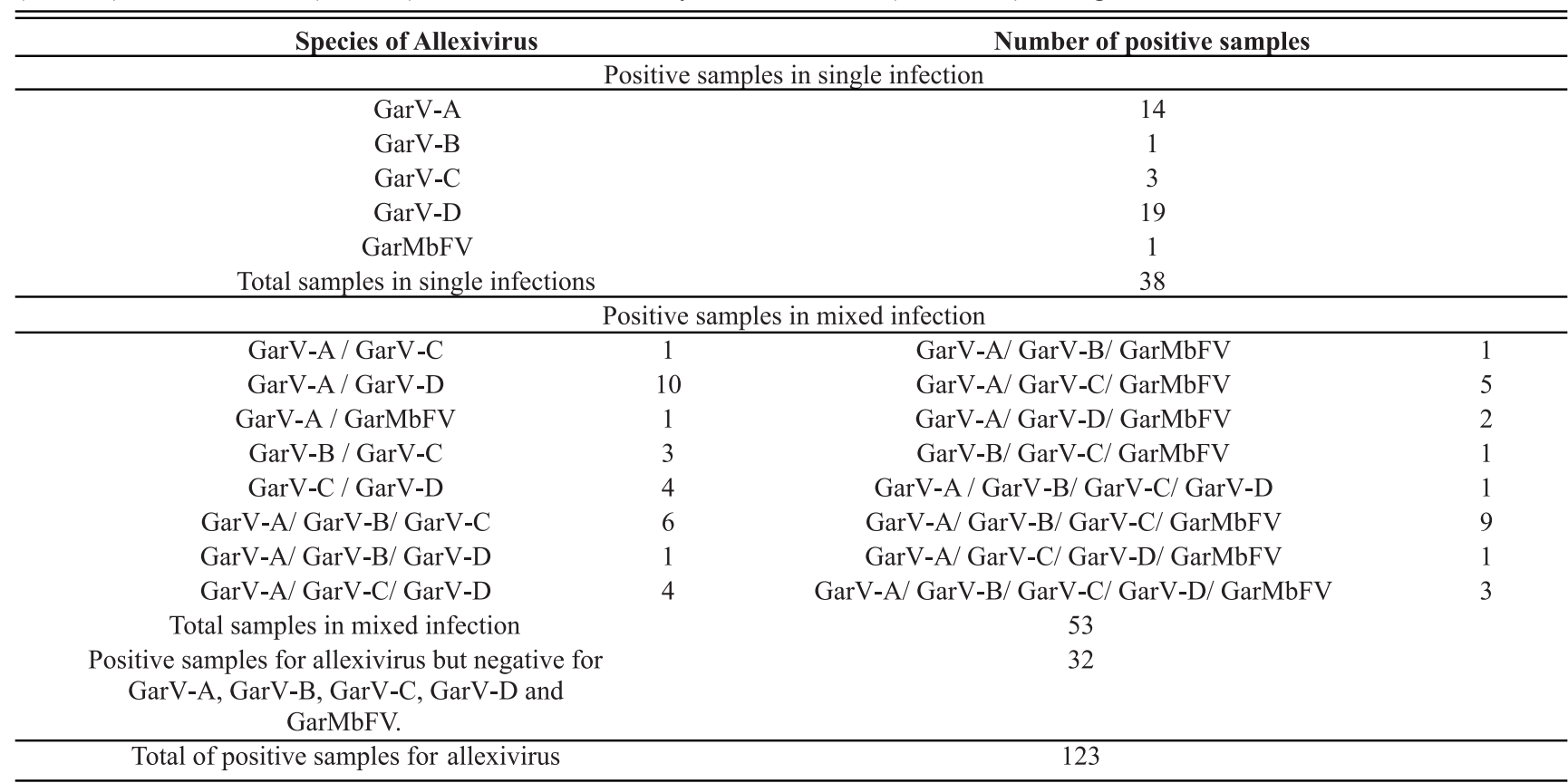

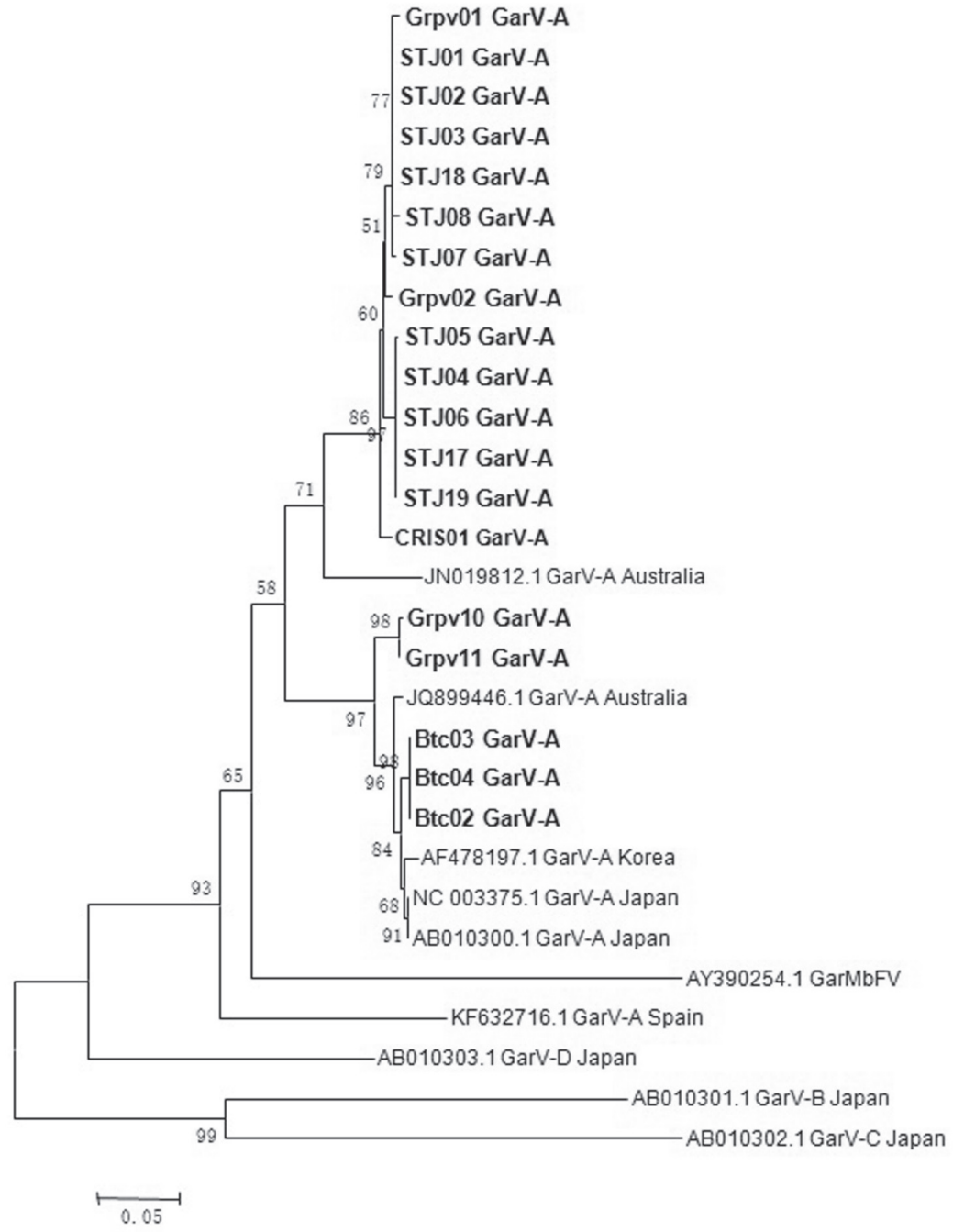

FIGURE 1 - Phylogenetic tree of the complete coat protein nucleotide sequence of the Brazilian Garlic virus A (GarV-A) sequences, all GarV-A sequences available at public nucleotide databases, and the reference sequences of other garlic-infecting allexiviruses. STJ, Santa Juliana (PR); Grpv, Guarapuava (PR); CRIS, Cristalina (GO); and Btc, Botucatu (SP). GenBank access numbers for the Brazilian isolates: JX488604-18, KF955560-63. 

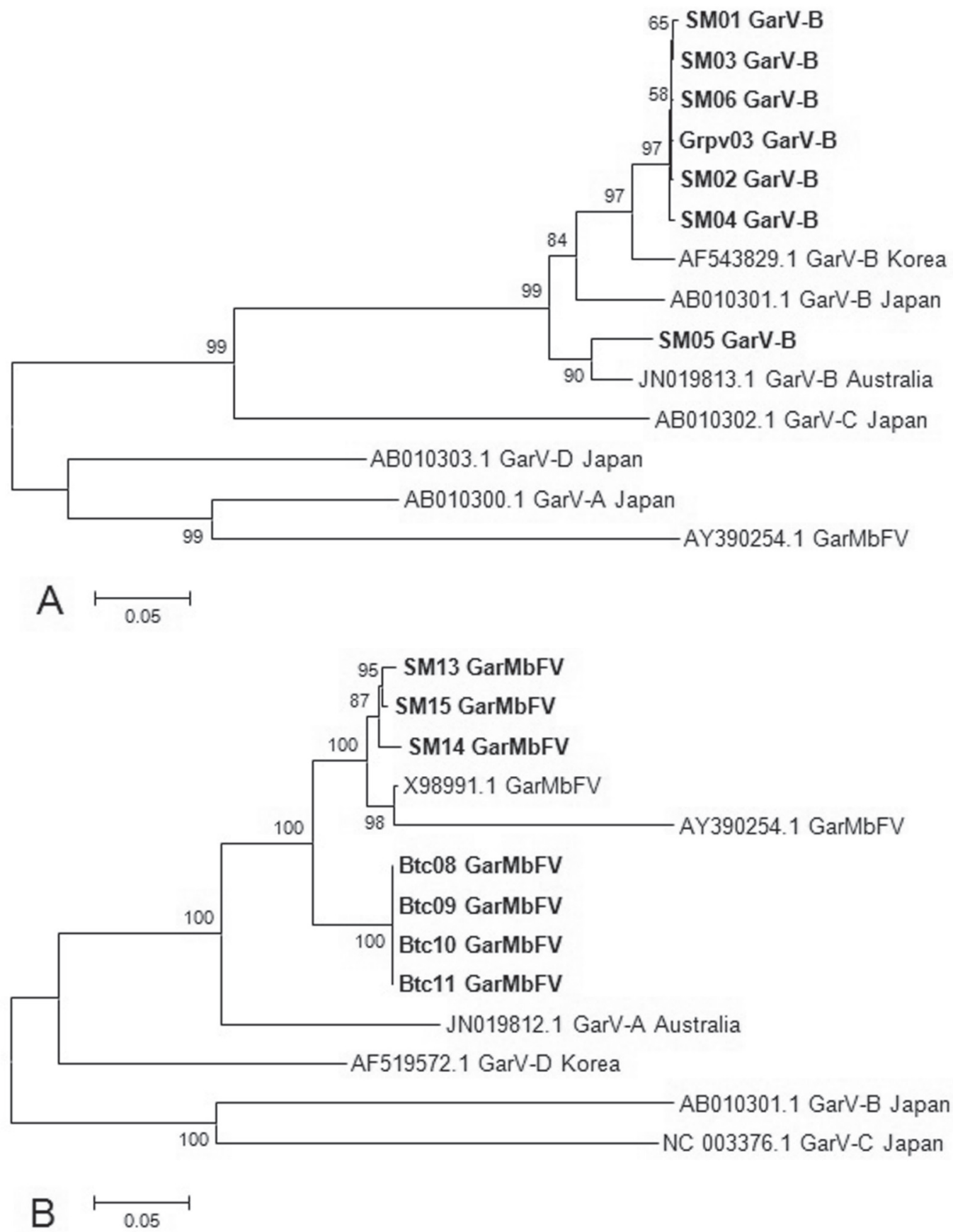

FIGURE 2 - Phylogenetic tree of the complete coat protein nucleotide sequence of the Brazilian Garlic virus B (GarV-B) (A) and Garlic mite-borne filamentous virus (GarMbFV) (B) isolates, all GarV-B and GaMbFV sequences available at public nucleotide databases, and the reference sequences of other garlic infecting allexiviruses. Grpv, Guarapuava (PR); SM, São Manuel (SP); and Btc, Botucatu (SP). GenBank access numbers for the Brazilian isolates: JX488619-25, KF955571-77.

isolates Grpv04 (JX488632), Grpv13 (JX488634), Grpv12 (JX488633) and SM07 (JX488626), Japanese isolates AB010302 and NC_003376 and one isolate from Australia (JQ899448) shared $97 \%$ to $98 \%$ nucleotide sequence identity. A low CP sequence identity (67\%) was observed between Brazilian isolates SM08 and SM11 compared with the Australian isolate JN019814, and this isolate was placed in a different branch in the phylogenetic tree (Figure 3A). Since nucleotide identity lower than $72 \%$ (or $80 \%$ amino acid identity) for the complete coat protein sequence is one of the criteria used by the ICTV to differentiate allexivirus species (Adams et al., 2012), our results indicate that only 


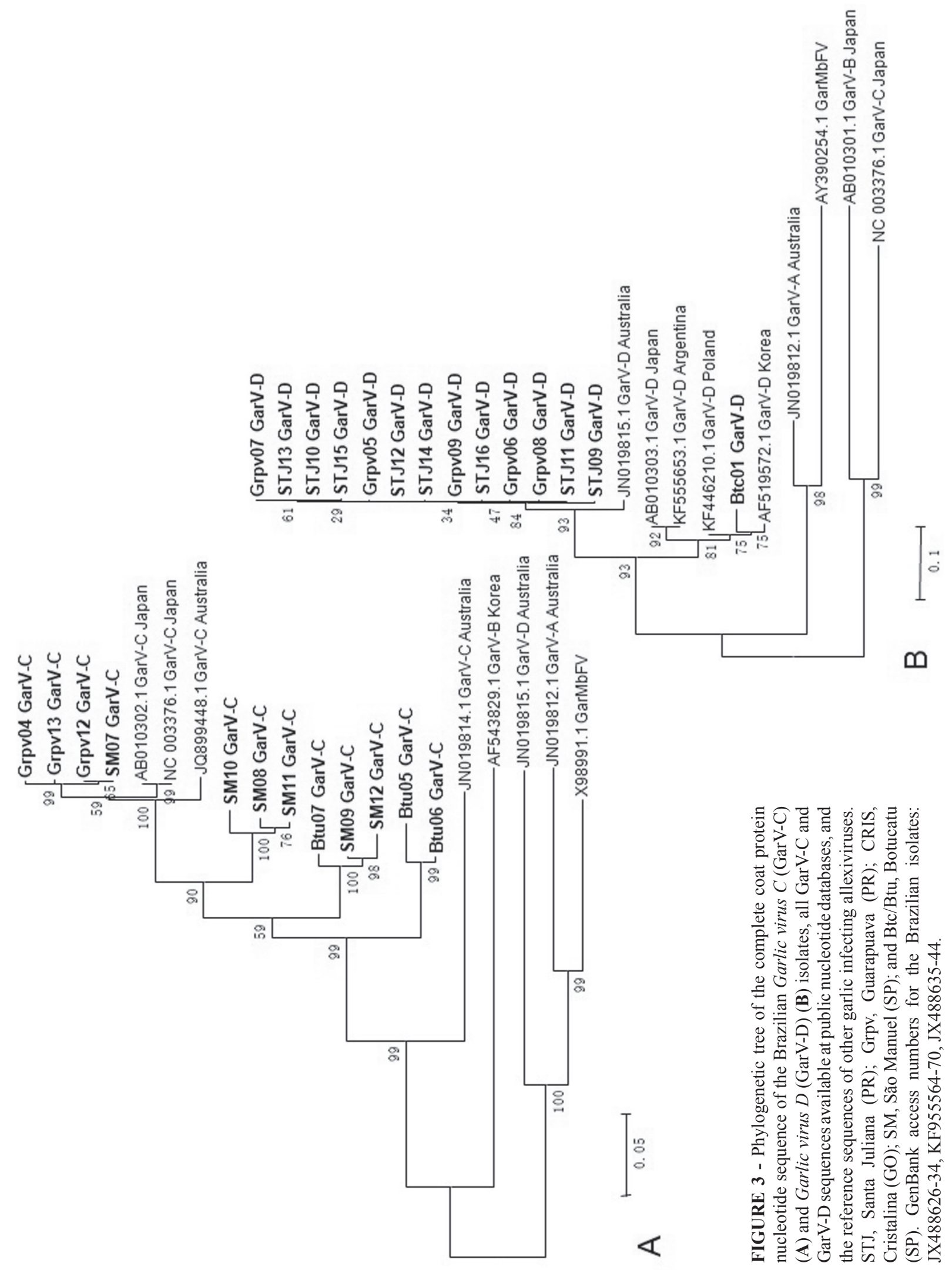


the analysis of the $\mathrm{CP}$ region of the allexivirus genome may not be sufficient to classify isolates in the same species, or that the isolate from Australia (JN019814) may not be classified as a GarV-C isolate.

Among 45 positive samples found for GarV-D, fourteen were selected for sequencing. The coat protein gene of the GarV-D isolates analyzed had $87 \%$ to $97 \%$ nucleotide identity. Most Brazilian isolates share the highest nucleotide identity (97\%) with the Australian isolate JN019815, while one isolate collected in Botucatu (SP) was closely related with an isolate from Korea (AF519572; Figure 3B), sharing 95\% nucleotide sequence identity.

Twenty-four samples were positive for GarMbFV and seven samples were selected for sequencing. Their $\mathrm{CP}$ nucleotide sequence identity ranged from $72 \%$ to 91\% with isolates deposited in GenBank. Two different monophyletic branches were formed. One includes three Brazilian isolates collected in São Manuel (SM13, KF955571; SM15, KF955573; SM14, KF955572), with 90\% identity with an isolate from Argentina (X98991) and $76 \%$ with an isolate from Korea (AY390254). The isolates collected in Botucatu (Btc08, KF955574; Btc09, KF955575; Btc10, KF955576; and Btc11, KF955577), grouped in the second branch (Figure 2B).

There are few studies on allexiviruses in Brazil, and yet according to our results allexiviruses seem to be an important component of the complex of viruses causing degeneration of garlic crops in the country due to their wide distribution in the most important producing areas. GarV-A was the species more frequently found in garlic plants in our sampling, and previous studies indicated that this species causes significant losses to garlic plants (Cafrune et al., 2006).

Trading of garlic bulbs imported from Europe, Asia and Argentina may have played an important role in virus introduction into the country (Melo Filho et al., 2004). Van Dijk et al. (1991) reported the presence of an allexivirus in onion plants originated from China and Spain, both exporting countries to Brazil. Part of the bulbs imported for consumption can also be used as seeds to establish new crops, being probably responsible for the introduction of new diseases in the country (Melo Filho et al., 2004).

The broad distribution and occurrence of garlic viruses reinforce the need of a garlic-seed certification program in Brazil, which is essential to improve the health conditions of the crop. In Brazilian conditions, plants originating from virus-free cloves reach up to 18 tones per hectare while bulbs infected with virus, which corresponds to most of the country garlic grown, 5-6 tones per hectare (M. A. Pavan and R. Krause-Sakate, unpublished results). Quality is also highly affected, as bulbs are small and not uniform. Thus the use of virus-free propagation material is strongly recommended, and it is essential that commercial crops be completely separated from propagation crops in order to avoid contamination.

\section{ACKNOWLEDGEMENTS}

This work was funded by Fundação de Amparo a Pesquisa do Estado de São Paulo - FAPESP, Brazil (grant numbers 2010/15370-0 and 2010/12965-2). We thank the garlic growers for samples collected and used in this work. Renate Krause Sakate and Marcelo Agenor Pavan are Conselho Nacional de Desenvolvimento Científico e Tecnológico - CNPq research fellows.

\section{REFERENCES}

Adams MJ, Candresse T, Hammond J, Kreuze JF, Martelli GP, Namba S, Pearson MN, Ryu KH, Vaira AM (2012) Family Alphaflexiviridae. In: King AMK, Lefkowitz E, Adams MJ, Carstens EB (Eds.) Virus Taxonomy - $9^{\text {th }}$ Report of the International Committee on Taxonomy of Viruses. London, UK. Elsevier. pp. 904-907.

AGRIANUAL (2012) Alho: produção brasileira (2011). São Paulo, SP. FNP Consultoria.

Cafrune EE, Perotto MC, Conci VC (2006) Effect of two Allexivirus isolates on garlic yield. Plant Disease 90:898904.

Bertheau Y, Fréchon N, Toth IK, Hyman, LJ (1998) DNA amplification by polymerase chain reaction (PCR). In: Pérombelon MCM, Van Der Wolff JM (Eds.) Methods for the Detection and Quantification of Erwinia carotovora subsp. atroseptica on Potatoes: a Laboratory Manual. Dundee, Scotland. Scottish Crop Research Institute. pp. 38-48.

Fayad-Andre MS, Dusi AN, Resende RO (2011) Spread of viruses in garlic fields cultivated under different agricultural production systems in Brazil. Tropical Plant Pathology 36:341-349.

Katis NI, Maliogka VI, Dovas CI (2012) Viruses of the genus Allium in the Mediterranean region. In: Loebenstein G, Lecoq H (Eds.) Viruses and Virus Diseases of Vegetables in the Mediterranean Basin. San Diego, CA, USA. Elsevier. pp. 163-208.

Melo Filho P, Nagata T, Dusi AN, Buso J, Torres AC, Eiras M, Resende RO (2004) Detection of three Allexivirus species infecting garlic in Brazil. Pesquisa Agropecuaria Brasileira 39:735-740.

Nascimento RJ, Pio-Ribeiro G, Santos RC, Melo Filho PA (2008) Detecção de allexivirus em primórdios foliares de alho via RT-PCR. Summa Phytopathologyca 34:267-269.

Oliveira ML, Hoffmann MIM, Mituti T, Pavan MA, KrauseSakate R (2014) First report of Garlic virus $X$ in garlic plants in Brazil. Plant Disease 89:1013.

Perotto MC, Cafrune EE, Conci VC (2010) The effect of additional viral infections on garlic plants initially infected with Allexiviruses. European Journal of Plant Pathology 126:489-495.

Van Dijk P, Verbeek M, Bos L (1991) Mite-borne virus isolates from cultivated Allium species, and their classification into two new rymoviruses in the family Potyviridae. European Journal of Plant Pathology 97:381-399.

Van Dijk P, Van der Vlugt RAA (1994) New mite-borne virus isolates from rakkyo, shallot and wild leek species. European 
Journal of Plant Pathology 100:269-277.

Wylie SJ, Luo H, Li H, Jones MGK (2012) Multiple polyadenylated RNA viruses detected in pooled cultivated and wild plant samples. Archives of Virology 157:271-284.

TPP-2014-0027

Submitted: 18 February 2014

Revisions requested: 18 March 2014

Accepted: 13 August 2014

Section Editor: Alice K. Inoue-Nagata 